\title{
PATRIMÔNIO RURAL, PAISAGENS AGRÍCOLAS E CONSTRUÇÃO DA SUSTENTABILIDADE EM RIBEIRÃO DO EIXO (MG): A NECESSIDADE DA EDUCAÇÃO VOLTADA À REALIDADE CULTURAL DOS ESTUDANTES CAMPONESES
}

\author{
Vagner Luciano de Andrade* \\ Veroni Friedrich**
}

RESUMO: No contexto sociopolítico brasileiro atual, é cada vez mais comum a submissão de comunidades e populações camponesas à realidade dos grandes centros urbanos. Esta é também a realidade de Ribeirão do Eixo, localidade rural do município de Itabirito, eixo sul de expansão urbana da Grande BH. Esta proximidade dos dois importantes polos urbanos é ampliada pela pressão do tráfego rodoviário da BR040, por empreendimentos imobiliários, industriais e minerários, que contribuem demasiadamente para a perda da identidade local e descaracterização da paisagem natural, gerando expectativas fora daquela realidade, desvalorizando-a. A região espera pela definitiva preservação das Serras da Moeda e das Serrinhas, implantação de uma estrada parque entre as regiões do Pico e da Fábrica e um posto de fiscalização da Polícia Ambiental em conjunto com IEF, gestor de duas unidades de conservação na área. Além da importância ambiental, a região é detentora de paisagens culturais singulares ligadas à época do Brasil Colônia, principalmente aos primórdios auríferos. Neste sentido, o presente estudo propõe intervenções pautadas em princípios de identidade, sustentabilidade, agroecologia, ecoturismo, ruralidade e cultura que contribuam para a ressignificação e devida valorização ambiental e cultural da localidade por todos que nela vivem, trabalham, ou apenas passam períodos.

PALAVRAS-CHAVE: Campesinato; Educação do Campo; Escola Camponesa.

\footnotetext{
Discente do Curso de Licenciatura em História (EAD) pelo Centro Universitário de Maringá (UNICESUMAR), Brasil. E-mail: trezeagosto@yahoo.com.br

* Mestre em História com concentração no tema "Patrimônio Cultural". Docente da Educação Básica do Estado do Paraná e Centro Universitário de Maringá (UNICESUMAR), Brasil.
} 


\section{RURAL HERITAGE, AGRICULTURAL LANDSCAPES AND THE CONSTRUCTION OF SUSTAINABILITY IN RIBEIRÃO DO EIXO, BRAZIL: EDUCATION FOR THE CULTURAL NEEDS OF FARMERS OFFSPRING}

ABSTRACT: The submission of rural communities and population to great urban centers is common within the current socio-political context in Brazil. The community of Ribeirão do Eixo, in the municipality of Itabirito MG Brazil, on the southern section of urban expansion of the Great Belo Horizonte, is no exception. Closeness of two important urban poles, increased by great traffic on the highway BR-40, through real estate, industries and mining companies contributes towards the loss of local identity and the de-characterization of the natural landscape, with great expectations and devaluation. The region's population expects the preservation of the Serras da Moeda and Serrinhas, the establishment of a park between the Pico and Fabrica regions and an Environmental Police Post with IEF, the administrator of the two conservation units in the region. The region is also characterized by unique cultural landscapes linked to Colonial Brazil, especially during the $17^{\text {th }}$ century gold-rush. Current analysis suggests interventions based on identity principles, sustainability, agroecology, ecoturism, rurality and culture that would contribute towards environmental re-signification and cultural valorization of the region for its inhabitants, workers and tourists.

KEY WORDS: Farmers; Rural education; Rural schooling.

\section{INTRODUÇÃO}

Especialmente após a consolidação do sistema socioeconômico vigente, a paisagem rural foi considerada como dependente e submissa, e, diante disso, o campo se tornou culturalmente atrasado e sinônimo de retrocesso em relação às cidades. Um fato imposto a inúmeras comunidades rurais, exploradas como ambientes produtores de recursos naturais, direcionados ao crescente consumismo da sociedade. Mas para haver ascensão da sustentabilidade no campo, necessita-se revisar os atuais padrões sociais vigorantes no meio agrário, visando uma imediata revisitação dos mesmos.

Este trabalho expõe a realidade de uma escola no campo, da comunidade 
rurbana adjacente e de seus moradores, retomando a discussão em torno da constituição da sustentabilidade camponesa, pautada principalmente na ressignificação dos patrimônios cultural e natural como meios efetivos de fixação do agricultor familiar. Como objetivos específicos: $1^{\circ}$ ) questionou o modelo de formação do cidadão rural protagonizada atualmente na educação convencional, que reproduz ideias concebidas na urbe; $2^{\circ}$ ) entendeu como as dinâmicas presentes no espaço rural são diferentes do contexto urbano; e $3^{\circ}$ ) ressaltou como o projeto político-pedagógico da escola no meio rural reproduz claramente ideias e conhecimentos voltadas à realidade dos moradores das cidades.

Metodologicamente, a pesquisa realizou um amplo levantamento bibliográfico sobre o tema, no sentido de contribuir futuramente para uma revisão de literatura e encaminhamentos subsequentes. Para o conhecimento da realidade de descaracterização do espaço rural em detrimento do tecido urbano elencou-se uma localidade ao Sul da capital mineira denominada Ribeirão do Eixo, em Itabirito (MG) e seus sujeitos socioculturais. A pesquisa iniciou-se no âmbito da Licenciatura em Educação do Campo com habilitação em Ciências Sociais e Humanidades (docência de Filosofia, Geografia, História e Sociologia) ofertada pela FAE/UFMG em 2012 e a escola camponesa da localidade foi alvo de observações didático-pedagógicas que culminaram na publicação de um artigo de opinião no Boletim da UFMG, datado de 04 de junho de 2012. Assim, buscando aplicar estes questionamentos à realidade estudada, o projeto inicial se desdobrou em diversas etapas, em uma abordagem quantitativa, tendo em vista a coleta de dados realizada sistematicamente: $1^{\mathrm{a}}$ etapa: proposta de intervenção; $2^{\mathrm{a}}$ etapa: caracterização do município e da comunidade;

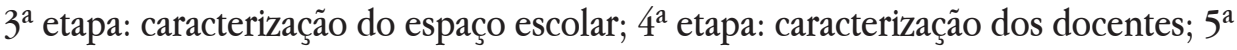
etapa: caracterização da coordenação; $6^{\mathrm{a}}$ etapa: caracterização dos alunos; $7^{\mathrm{a}}$ etapa: caracterização dos pais/moradores; $8^{a}$ etapa: caracterização dos funcionários. Assim, gradativamente, em cada etapa foram aplicados questionários e entrevistas e, ao fim da última, os resultados foram formatados e entregues à FAE/UFMG. Posteriormente, com o desligamento de curso, a pesquisa precisava continuar e os trabalhos foram retomados no ano de 2016, no âmbito da disciplina Estudo de Caso em Agronegócio ofertada na graduação em Tecnologia em Gestão do Agronegócio da Universidade do Sul de Santa Catarina (UNISUL). A ideia era realizar uma pesquisa sobre 
Ruralidade, Educação e Turismo como atividade complementar obrigatória visando integralização curricular da Licenciatura em História, modalidade EAD, do Centro Universitário de Maringá (UNICESUMAR), em curso.

Assim, o projeto da pesquisa foi revisitado e teve, além do levantamento de dados, atividades sequenciais, mas qualitativas, com uma base mais fenomenológica, a partir dos eventos, fenômenos e processos que compunham a realidade da respectiva comunidade rural. Aplicaram-se à discussão inicial questões teóricas inerentes à paisagem e ao patrimônio local. Notou-se que a educação, ofertada apenas nos anos iniciais da educação básica, não preparavam o cidadão camponês local para sua realidade. Os alunos saem deste lugar para a cidade de Congonhas (MG) para completarem a formação da educação básica. Desse modo, pautado em princípios de identidade, sustentabilidade, agroecologia, ecoturismo, ruralidade e cultura, várias propostas para a comunidade foram evidenciadas, em especial a de uma escola politécnica agrícola aproveitando o espaço escolar já existente, em turnos alternativos, oferecendo inicialmente cursos técnicos nas áreas de agropecuária, ecologia e turismo.

\section{MATERIAIS E MÉTODOS}

A sociedade capitalista moderna acentua processos de alienação, degradação, dominação, exploração, fragmentação e globalização. Neste contexto contrário à sustentabilidade, humanidade e recursos naturais são aceitáveis aos ditames e processos existentes, apenas por suas características mercadológicas. O estabelecimento do modelo socioeconômico vigente amplia continuamente o consumo exarcebado e a exploração da natureza (OLIVEIRA, 2002). Assim, a descaracterização de paisagens, culturas e patrimônios se intensificaram devido à extração de matéria -prima transformada em bens de consumo. Com o advento das revoluções industrial e tecnológica, a constante industrialização e urbanização dilapidam espaços naturais e comunidades tradicionais. São interesses minoritários de lucro e poder que desprezam interesses coletivos necessários a todos. Neste contexto urbano-industrial capitalista, a cultura rural foi ignorada é considerada como sinônimo de atraso e 
retrocesso. Gradativamente, o campo se tornou dependente e submisso em relação às necessidades das cidades (ANDRADE, 2016). Para Barreiro (2010, p. 28):

O aumento da migração campo/cidade passou a constituir-se em desequilíbrios, por causa do esvaziamento do campo e do onseqüente "inchaço" urbano, agravados pela desqualificação profissional da população rural nas cidades. Diante disso, a educação rural passou a ser vista como possibilidade de valorização de vida no campo para minimizar o processo de migração, desconsiderando, no entanto, questões estruturais determinantes da condição de vida da população migratória. A educação rural baseou-se nos pressupostos do ruralismo pedagógico, tendência educacional que credita à ampliação dos conhecimentos do homem do campo o aumento das possibilidades de fixá-lo à terra.

Um episódio historicamente imposto a inúmeras comunidades rurais tradicionais. Para se atender aos ditames capitalistas, grandes empreendimentos se apropriaram de áreas significativas em termos de recursos naturais tornando-os espaços produtores direcionados ao crescente consumo da sociedade. Neste contexto, o patrimônio ambiental destes agrupamentos é predado, as paisagens locais são descaracterizadas, desrespeitando a cultura das comunidades ancestralmente instaladas. Em termos ecológicos, a capacidade de suporte dos ecossistemas é saturada resultando em significativos problemas socioambientais como a mineração, por exemplo (Figura 01). Dentro desta lógica, surgem múltiplas desordens dentro da configuração e da dinâmica espacial preexistente. O espaço camponês e o meio urbano entram em embate, no qual contracenam, de um lado, grandes produtores rurais, latifundiários ansiosos por lucro e, do outro, pequenos agricultores ligados à terra, na qual obtêm o "suado" sustento.

Diante do consumismo, da dilapidação ambiental, das incertezas e ausências de perspectivas, das disparidades sociais, resta ao pequeno produtor uma escolha: ou resistir, mantendo seu vínculo harmônico com a terra de seus ancestrais, ou sucumbir atendendo a voracidade do sistema opressor. Se a alternativa escolhida for à segunda, restará um único caminho: a contínua exploração das matérias-primas até a exaustão, criando o rompimento definitivo com a realidade rural, levando-o a procurar por novas oportunidades na cidade (ANDRADE, 2012, p. 02) 


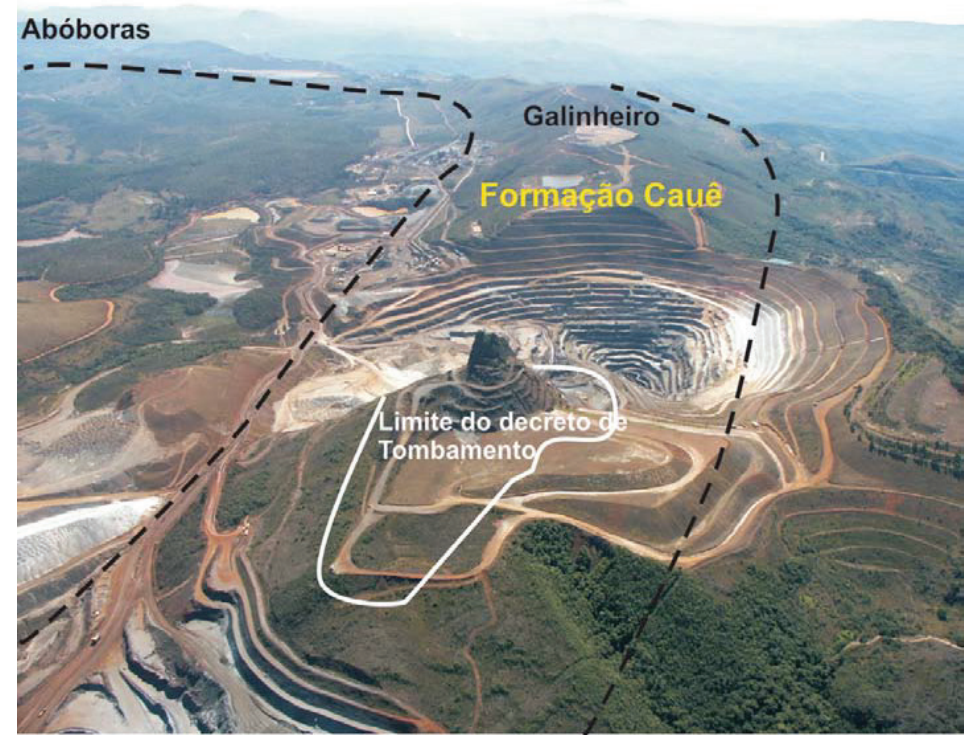

Figura 1. Destruição minerária no entorno do Pico do Itabira, localizado em Ribeirão do Eixo e declarado como patrimônio do Estado de Minas Gerais Fonte: Andrade (2016).

O aumento da produção agrícola é política prioritária que silenciosamente descontrói condições dignas de um campesinato excluído e marginalizado das decisões maiores que regem o país. Uma nova configuração espacial se formata no campo, voltada à intensa exploração e produção, com significativa mecanização agrícola, implantação de monoculturas, concentração de terras. O pequeno agricultor familiar, sem assistência técnica e sem instrumentos e mecanismos de competir com grandes produtores, é gradativamente expulso de suas paisagens ancestrais (ANDRADE, 2016). Esse desterro camponês traz rompimentos com uma cultura tradicionalmente ancestral de contato sustentável com a terra. Os atrativos da cidade grande são vislumbrados e criam-se fantasias que se transformarão em exclusão e frustração (ANDRADE; COSTA, 2015). Ao se dirigir aos grandes centros urbanos, buscando melhorias, lhes faltarão qualificação, emprego, perspectivas.

$\mathrm{Na}$ história de produção do espaço urbano brasileiro, famílias camponesas foram inseridas nas periferias, sem direito a condições mínimas de dignidade e qualidade de vida, comuns na égide da sociedade atual. Mas para que se promova 
sustentabilidade camponesa, os atuais padrões sociais vigentes no campo devem ser imediatamente revisitados e revistos (ANDRADE, 2012). Os índices de alienação cultural, degradação ambiental, dominação social e exploração econômica se contrapõem ao artigo 28 da LDBEN - Lei de Diretrizes e Bases da Educação Nacional, instituída pela Lei Federal no 9.394, de 20 de dezembro de 1996, que afirma:

Art. 28. Na oferta de educação básica para a população rural, os sistemas de ensino promoverão as adaptações necessárias à sua adequação às peculiaridades da vida rural e de cada região, especialmente:

I - conteúdos curriculares e metodologias apropriadas às reais necessidades e interesses dos alunos da zona rural;

II - organização escolar própria, incluindo adequação do calendário escolar às fases do ciclo agrícola e às condições climáticas;

III - adequação à natureza do trabalho na zona rural.

Parágrafo único. O fechamento de escolas do campo, indígenas e quilombolas será precedido de manifestação do órgão normativo do respectivo sistema de ensino, que considerará a justificativa apresentada pela Secretaria de Educação, a análise do diagnóstico do impacto da ação e a manifestação da comunidade escolar.

A importância da escola na paisagem rural como instrumento de reafirmação e de legitimização de identidades culturais expressa-se ainda no parágrafo único incluído pela Lei $n^{0} 12.960$, instituída em 27 de março de 2014, que, por sua vez, atesta que "o fechamento de escolas do campo, indígenas e quilombolas será precedido de manifestação do órgão normativo do respectivo sistema de ensino, que considerará a justificativa apresentada pela Secretaria de Educação, a análise do diagnóstico do impacto da ação e a manifestação da comunidade escolar".

\section{RESULTADOS E DISCUSSÕES}

Este trabalho teve por objetivo geral expor a realidade de uma comunidade e de seus habitantes, retomando a discussão em torno da construção da sustentabilidade no campo, pautada principalmente na valorização dos patrimônios cultural e natural como meios efetivos de fixação do agricultor familiar. Como objetivos específicos, delimitou-se: $1^{\circ}$ ) questionar o modelo de formação do cidadão rural protagonizada atualmente na educação convencional, que reproduz ideias concebidas 
na cidade; $2^{\circ}$ ) entender como as dinâmicas presentes no meio rural são diferentes do contexto urbano; e $3^{\circ}$ ) ressaltar como o projeto político-pedagógico da escola no meio rural reproduz claramente ideias e conhecimentos voltadas à realidade dos moradores das cidades.

Metodologicamente, a pesquisa realizou um amplo levantamento bibliográfico sobre o tema, no sentido de contribuir futuramente para uma revisão de literatura e encaminhamentos subsequentes. Para o conhecimento da realidade de descaracterização do espaço rural em detrimento do tecido urbano elencou-se uma localidade ao Sul da capital mineira denominada Ribeirão do Eixo, em Itabirito (MG) (Figura 2). A escola camponesa da localidade foi alvo de observações didático-pedagógicas pautadas em princípios de identidade, sustentabilidade, agroecologia, ecoturismo, ruralidade e cultura.

\section{ITABIRITO}

FONTE: IBGE | PERFIL SOCIECONOMICO 2015 - FECOMERCIO
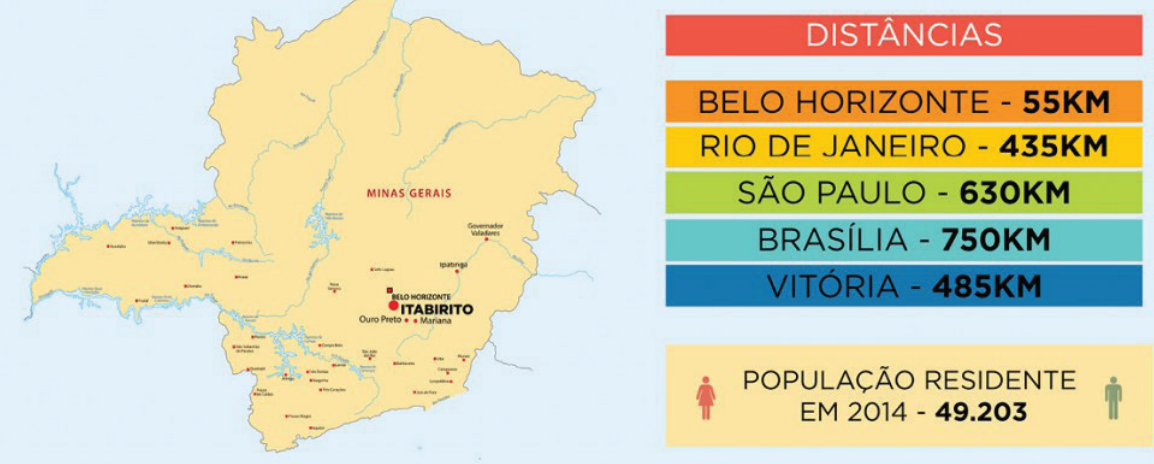

Figura 2. Localização de Itabirito no Brasil e em Minas Gerais Fonte: http://www.itabirito.mg.gov.br/descubra-itabirito/dados-geograficos (2017).

Estas intervenções foram inicialmente planejadas e realizadas dentro do Programa Institucional de Bolsas de Iniciação à Docência (PIBID), no âmbito do Curso de Licenciatura em Educação do Campo (Habilitação Ciências Sociais e Humanidades), ofertado pela Faculdade de Educação (FAE) da Universidade Federal de Minas Gerais (UFMG), e foi desenvolvido entre maio de 2012 e abril de 2013 
com apoio da Rede Ação Ambiental. Inicialmente percebeu-se uma comunidade sem identidade, em um território que transita por nuances urbanas, rurais, industriais, minerárias e naturais. A escolha do local se deve à existência do Pico Itabirito (Figura 03), patrimônio cultural do Estado de Minas Gerais, de acordo com a Lei estadual $\mathrm{n}^{\mathrm{O}}$ 10.726, de 12 de maio de 1992, e degradado pela mineração.

Estabelece os limites da área de conservação do pico do Itabirito e dá outras providências.

O Povo do Estado de Minas Gerais, por seus representantes, decretou e eu, em seu nome, sanciono a seguinte Lei:

Art. $1^{\circ}$ - Ficam estabelecidos, nos termos do $\S 1^{\circ}$ do artigo 84 do Ato das Disposições Constitucionais Transitórias da Constituição do Estado, como definidores da área de demarcação do pico do Itabirito, descrita graficamente e em coordenadas UTM, os seguintes limites: começa no ponto 1 , coordenada norte $7.761 .286,729$ e coordenada leste $618.155,626$; ponto 2 , coordenada norte $7.761 .392,595$ e coordenada leste 618.221,141; ponto 3, coordenada norte 7.761.434,004 e coordenada leste 618.254,654; ponto 4, coordenada norte 7.761.412,467 e coordenada leste $618.320,470$; ponto 5 , coordenada norte $7.761 .389,317$ e coordenada leste $618.360,289$; ponto 6 , coordenada norte $7.761 .457,566$ e coordenada leste $618.445,112$; ponto 7, coordenada norte 7.761.496,926 e coordenada leste 618.461,820; ponto 8, coordenada norte 7.761.582,261 e coordenada leste 618.463,346; ponto 9, coordenada norte 7.761.619,666 e coordenada leste 618.438,201; ponto 10 , coordenada norte 7.761.639,634 e coordenada leste $618.407,741$; ponto 11 , coordenada norte 7.761.627,632 e coordenada leste $618.329,018$; ponto 12 , coordenada norte $7.761 .608,208$ e coordenada leste $618.298,748$; ponto 13 , coordenada norte 7.761.591,584 e coordenada leste 618.261,264; ponto 14, coordenada norte 7.761.581,338 e coordenada leste $618.229,620$; ponto 15 , coordenada norte $7.761 .583,500$ e coordenada leste 618.186,000; ponto 16 , coordenada norte $7.761 .508,000$ e coordenada leste $618.133,000$; ponto 17 , coordenada norte $7.761 .454,000$ e coordenada leste $618.188,000$; ponto 18 , coordenada norte 7.761.377,000 e coordenada leste 618.106,000; ponto 19, coordenada norte 7.761.370,500 e coordenada leste 618.099,000; e ponto 20, coordenada norte 7.761.331,500 e coordenada leste $618.085,000$. Do ponto 20, segue contornando a estrada indicada na planta até o ponto 1 , coordenada norte 7.761.286,729 e coordenada leste $618.155,626$. As coordenadas referidas na descrição acima são topográficas com origem em Marco UTM, denominado Salvador Machado, com coordenada norte $7.762 .550,749$ e coordenada leste $619.055,110$. O ponto de origem para correlação das coordenadas 
tem no sistema de coordenadas da rede Saint John Del Rey Mining Company a coordenada norte 48.192,306 e a coordenada leste 22.920,340, e, no sistema de coordenadas UTM, a coordenada norte 7.762.269,671 e a coordenada leste 618.900,375.

Art. $2^{\circ}$ - Fica autorizado o Instituto Estadual do Patrimônio Histórico e Artístico - IEPHA-MG - a inscrever em seu livro de Tombo Arqueológico, Etnográfico e Paisagístico, previsto no artigo $4^{\circ}$ da Lei $\mathrm{n}^{\circ} \mathbf{5 . 7 7 5}$, de 30 de setembro de 1971, e no artigo $4^{\circ}$, inciso I, do Decreto $\mathrm{n}^{\mathrm{o}}$ 14.374 , de 10 de março de 1972, o pico de que trata esta lei, situado no Município de Itabirito, observados os limites descritos no artigo anterior.

Art. $3^{\circ}$ - O plano de recuperação da área degradada, nos limites geográficos estabelecidos nesta Lei, será aprovado pelo órgão ambiental competente, conforme a legislação em vigor, e executado pela empresa mineradora responsável pela degradação.

Art. $4^{0}$ - Esta Lei entra em vigor na data de sua publicação.

Art. $5^{\circ}$ - Revogam-se as disposições em contrário.

Dada no Palácio da Liberdade, em Belo Horizonte, aos 12 de maio de 1992.

HÉLIO GARCIA

Evandro de Pádua Abreu

Maria Celina Pinto Albano

Kildare Gonçalves Carvalho

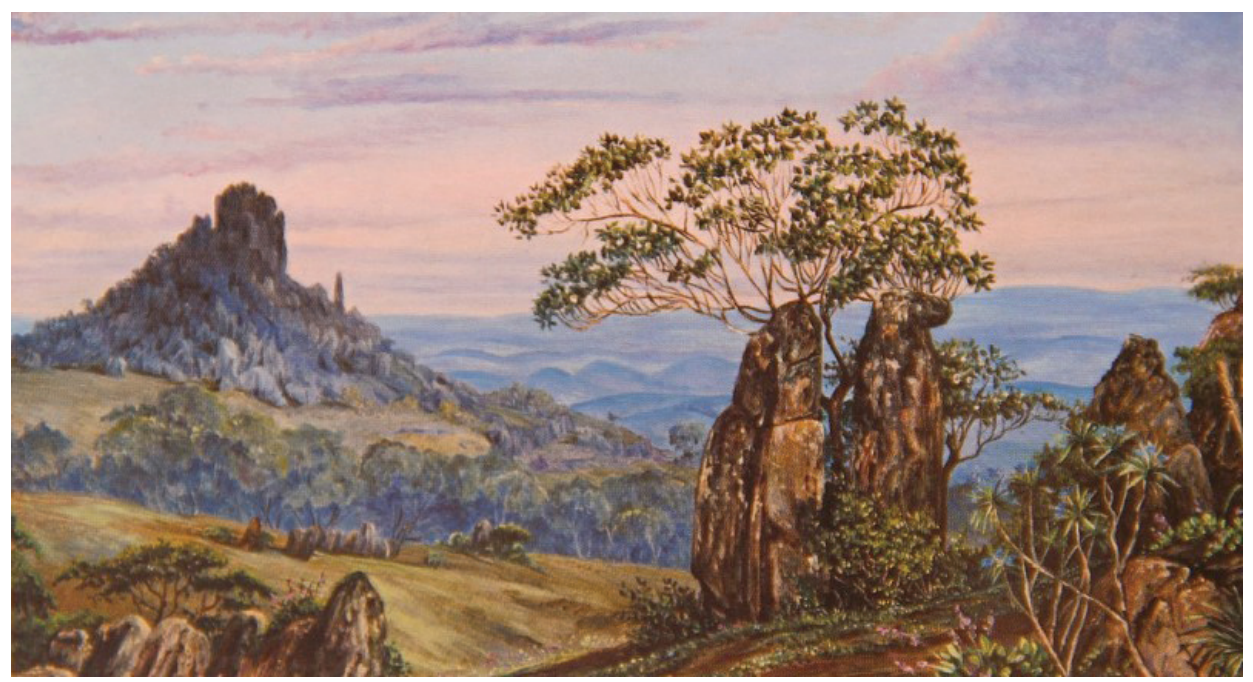

Figura 3. Pico do Itabirito, em pintura de Marianne North, pintora inglesa do Século XIX Fonte: http://minutomais.com/itabirito/pintora-inglesa-do-seculo-19-retrata-itabirito-em-obras-queseduziram-darwin.html/attachment/pintura-de-marianne-north-para-o-livro-pico-de-itabirito-1 
É relevante lembrar que Faria Filho (2005) caracteriza a essência urbana da educação convencional. Segundo ele, estudos atestam "o fato de a escolarização na modernidade ser um fenômeno observado primeiramente nas cidades" e que 0 fortalecimento da escola como instituição de socialização está vinculado às grandes transformações citadinas na Europa a partir do século XVI e, no Brasil, a partir do século XIX. Quanto à natureza, a pesquisa a que se destina o Projeto conceituou-se como análise aplicada, uma vez que definiu novos métodos ou maneiras de conhecer a realidade rural a partir de vários questionamentos, tendo como referência 0 artigo 28 da LDBEN - Lei de Diretrizes e Bases da Educação Nacional (1996).

No que diz respeito ao método de pesquisa, afirma-se que o Projeto buscou responder a inúmeros questionamentos evidenciados por diferentes autores que abordaram o tema da educação rural e da educação camponesa (Figura 4): a educação convencional atrela-se à ideia de promoção da cidadania e sustentabilidade no campo? Há intenções de fixação do homem no campo? Os aspectos educacionais reproduzidos levam o pequeno camponês a valorizar o seu espaço? Ele é formado para atuar sobre sua realidade local, visando melhorias necessárias? A educação, como é proposta o incentiva a viver de ilusóes, querendo ir para as cidades à procura de melhoria da qualidade de vida? Esta melhoria seria possível no campo ou não e por quê? Há a devida formação voltada ao reconhecimento das potencialidades rurais? A natureza, maior patrimônio das comunidades é racionalmente manejada? A localidade, sua cultura, identidade e territorialidade são devidamente valorizadas?

Assim, buscando aplicar estes questionamentos à realidade estudada, o projeto inicial se desdobrou em diversas etapas, em uma abordagem quantitativa, tendo em vista a coleta de dados realizada sistematicamente: $1^{\mathrm{a}}$ etapa: proposta de intervenção; $2^{\mathrm{a}}$ etapa: caracterização do município e da comunidade; $3^{\mathrm{a}}$ etapa: caracterização do espaço escolar; $4^{\mathrm{a}}$ etapa: caracterização dos sujeitos socioculturais: docentes; $5^{\mathrm{a}}$ etapa: caracterização dos sujeitos socioculturais: coordenação; $6^{\mathrm{a}}$ etapa: caracterização dos sujeitos socioculturais: alunos; $7^{\mathrm{a}}$ etapa: caracterização dos sujeitos socioculturais: pais/moradores; $8^{a}$ etapa: caracterização dos sujeitos socioculturais: funcionários. Dessa forma, gradativamente, foram em cada etapa aplicados questionários e entrevistas e, ao fim desta última etapa, os resultados foram formatados e entregues à FAE/UFMG. Posteriormente, como houve desligamento de curso, 
a pesquisa precisava continuar e os trabalhos foram retomados no ano de 2016, no âmbito da Universidade do Sul de Santa Catarina (UNISUL) visando posterior aproveitamento como atividade complementar obrigatória no curso de Licenciatura em História (EAD) do Centro Universitário de Maringá (UNICESUMAR).

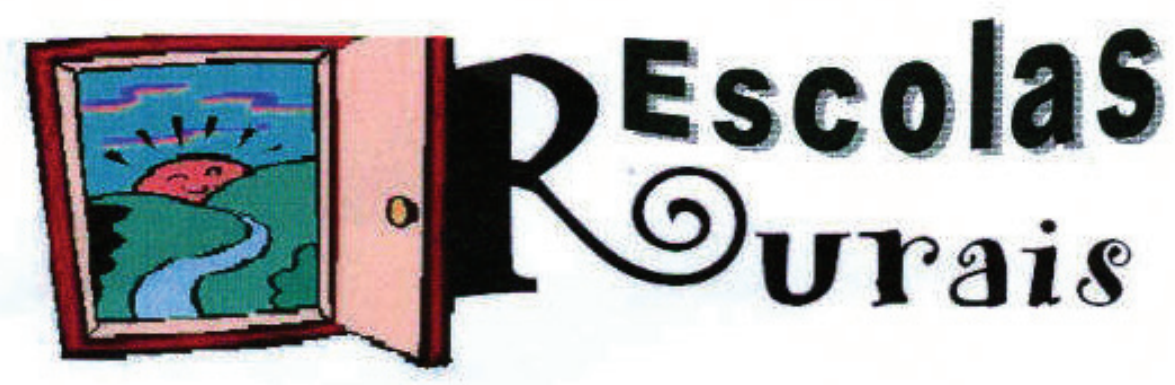

Escola: lugar de plantar e colher conhecimentos.

Figura 4. Emblema das escolas rurais de Itabirito

Fonte: Andrade (2016).

Assim, o projeto da pesquisa foi revisitado e teve, além do levantamento de dados, atividades sequenciais, mas qualitativas, com uma base mais fenomenológica, a partir dos eventos, fenômenos e processos que compunham a realidade da respectiva comunidade rural.

Neste contexto, as perguntas iniciais efetivamente verteram para se pensar na revisão e reestruturação imediatamente necessárias, do sistema educacional brasileiro, diferenciando-se as dinâmicas rurais das realidades urbanas e reforçando a construção de um modelo educativo rural baseado em uma formação socioambiental efetivadora da sustentabilidade no campo. Ao se analisar a comunidade e sua realidade verificou-se que um projeto educacional no contexto rural, em detrimento de uma maior proximidade entre homem e natureza, valoriza e protege o patrimônio ambiental (Figura 5), caracterizando-se como um conjunto de práticas e experiências sociais voltadas à promoção da inclusão e da cidadania, resultando na melhoria da qualidade de vida local. Se a realidade educacional no país é marcada por uma escola completamente desestruturada, tanto nas cidades como no campo, com altos 
níveis de retenção e evasão excluindo protagonistas de sua realidade social, no contexto agrário, a escola torna-se espaço de referência, ao integrar homem, sociedade e natureza, devido à proximidade de grandes áreas naturais ainda protegidas.

Diante disso, a pesquisa continuou na análise dos fatos apurados em campo, que examinados à luz de referenciais teóricos, construíram propostas efetiva para a resignificação da comunidade, em um sentido de identidade para com suas potencialidades e problemas. Notou-se que a educação, ofertada apenas nos anos iniciais da educação básica, não prepara o cidadão camponês para sua realidade. Estes alunos saem do lugar e vão para a cidade de Congonhas (MG) para completarem a formação. Assim, várias propostas para a comunidades foram evidenciadas, em especial a de uma escola politécnica agrícola aproveitando o espaço da escola já existente, em turnos alternativos, oferecendo curso técnico nas áreas de agropecuária, ecologia e turismo.

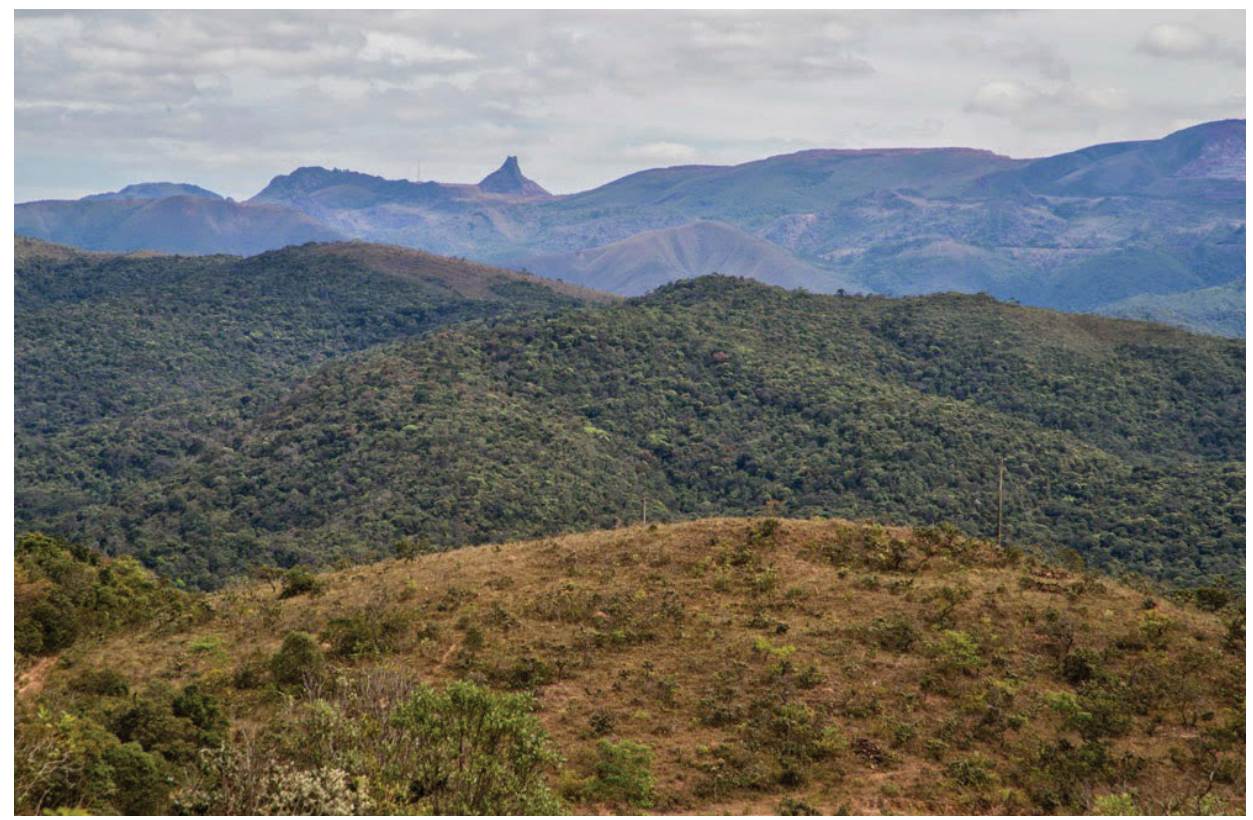

Figura 5. Paisagens rurais e Patrimônio natural no entorno do Pico de Itabirito Fonte: http://cbhvelhas.org.br/noticias/situacao-na-regiao-do-rompimento-da-barragem-preocupacbh-rio-das-velhas/ 


\section{CONCLUSÃO}

A partir deste estudo espera-se que alguns resultados apontem para novos horizontes, tendo como exemplo e referência pedagógica, a Faculdade de Educação da Universidade Federal de Minas Gerais, pioneira ao empreender um curso de formação voltado ao atendimento das demandas educativas rurais sob orientação do Ministério da Educação e do Desporto, denominado "Pedagogia da Terra".

Esta histórica conquista resultou na discussão, organização e implantação, a partir do $1^{\circ}$ semestre de 2009 , do primeiro curso de graduação em licenciatura camponesa a ser direcionado aos professores rurais sem formação, preenchendo uma lacuna sociocultural até então despercebida da sociedade brasileira. Que inúmeros cursos similares sejam oferecidos nas cidades do interior mineiro, facilitando o acesso de novos educadores rurais ao processo de formação docente condizentes com suas realidades de atuação. E como diria a música de Gilvan Santos, "eu não vou sair do campo pra poder ir à escola, educação do campo é direito, e não esmola", a revisão dos padrões educacionais vigentes no contexto rural implica, sobretudo, no rompimento com a educação convencional, baseado na vida urbana e consumista e reprodutora das ideias capitalistas dominantes.

Diante deste modelo educacional essencialmente urbano, a educação no meio rural prioriza a formação da percepção ambiental dos alunos e não somente uma compreensão social fragmentada pelo caráter antropocêntrico da educação convencional, sendo referência na construção de um novo padrão relacional entre ser humano e meio ambiente. Neste sentido, pautado na construção da sustentabilidade no campo, o meio rural precisa de uma formação educacional que permita aos alunos a vivência de instrumentos e mecanismos de ação, objetivando a transformação local, efetivando sua fixação, pleno desenvolvimento rural e o reconhecimento de potencialidades que minimizem os efeitos perversos do sistema socioeconômico, harmonizando o processo de apropriação dos recursos naturais. Por terem o seu público-alvo oriundo do meio rural, apresenta relevantes elementos de integração e harmonia entre ser humano e meio ambiente, que mesmo vivendo em função das cidades e do consumo, se refazem e se reafirmam.

Frente a isso, a revisão do atual modelo de educação aplicado nas realidades rurais visa que alunos compreendam o meio rural como um lugar onde a relação 
homem-natureza ainda não foi totalmente rompida pela atual sociedade consumista, egoísta e imediatista, levando-os o valorizarem o campo e a natureza, para atuarem em prol da valorização da cultural local de suas comunidades.

$\mathrm{Na} 1^{\mathrm{a}}$ fase, concluída no segundo semestre de 2016, houve a finalização de resultados parciais sistematizados no trabalho intitulado "PATRIMÔNIO CULTURAL, PAISAGENS ECOLÓGICAS E DESENVOLVIMENTO RURAL: perspectivas agroturísticas na escola da comunidade de Ribeirão do Eixo, município de Itabirito, região sudoeste do Quadrilátero Ferrífero, MG". A pesquisa buscou relações entre Patrimônio e Turismo na perspectiva da Educação sob orientação do Professor Mestre José Gabriel da Silva, Agrônomo pela UFSC, mestre em Agronomia (Física do Ambiente Agrícola) pela USP e aperfeiçoamento em Mudanças Climáticas pela Japan International Cooperation Agency. O respectivo professor é coordenador dos cursos de Engenharia Ambiental/Sanitária e Agronegócio, ambos pela Universidade do Sul de Santa Catarina (SC).

Disponibilizando à escola camponesa e à comunidade de Ribeirão do Eixo um inventário de Ecologia, Geografia e História para o subsídio de ações na mesma dentro do contexto de zona urbana especial do município de Itabirito, região do Quadrilátero Ferrífero, Minas Gerais, potencializando em sua realidade a ecologia, memória e paisagem rural, como meios promotores de uma nova realidade. Assim apresentou-se algumas propostas de desenvolvimento local, de resignificação desta localidade, dando ênfase à melhoria de qualidade de vida de seus moradores, com destaque na implantação de uma escola politécnica agroecológica em suas adjacências ser denominada ESCADA - Escola de Sustentabilidade, Conservação Ambiental e Desenvolvimento Agrário.

$\mathrm{O}$ estudo de caso estrutura-se teoricamente em cinco disciplinas regularmente cursadas no curso de Turismo da UNISUL: Cooperativismo Rural, Desenvolvimento Rural Integrado, Patrimônio Cultural e Natural, Patrimônio Natural e Turismo e Planejamento e Gestão de Negócios Agroturísticos. A matrícula na disciplina "Estudo de Caso", regularmente ofertada no Curso de Tecnologia em Agronegócio em AACA - Atividades Acadêmicas e Curriculares Adicionais da UNISUL, objetiva a realização de um Trabalho de Conclusão de curso, que por sua vez não é ofertado na estrutura curricular do curso de História do UNICESUMAR. Além da realização da 
pesquisa para a obtenção futura do título de licenciado em História, este trabalho também objetiva o cumprimento de créditos obrigatórios indispensáveis à integralização curricular e consecutiva colação de grau.

\section{REFERÊNCIAS}

ANDRADE, V.L. A Educação do Campo nas Séries Iniciais do Ensino Fundamental na Escola Municipal de Ribeirão do Eixo, Zona Rural de Itabirito, Minas Gerais: $1^{\mathrm{O}}$ relatório de observações. Universidade Federal de Minas Gerais - Faculdade de Educação - FAE/UFMG (Curso de Licenciatura em Educação do Campo - Habilitação Ciências Sociais e Humanidades). Belo Horizonte, 2012. 23p.

\section{ANDRADE, V.L. Patrimônio Cultural, Paisagens Ecológicas e Desenvolvimento}

Rural: potencial agroturístico na escola da comunidade de Ribeirão do Eixo, município de Itabirito, região sudoeste do Quadrilátero Ferrífero, MG. Universidade do Sul de Santa Catarina Palhoça, 2016. 150p. (Estudo de Caso Agronegócio).

ANDRADE, V. L. A educação como valorização do espaço rural. Boletim da UFMG $\mathrm{n}^{\mathrm{O}} 1778$, Ano 38, 2012. p. 02

BARREIRO, I. M. F. Política de educação no campo: para além da alfabetização (1952-1963). São Paulo: Cultura Acadêmica, 2010.

COSTA, L.; ANDRADE, V.L. Cultura, identidade e territorialidade camponesa. Boletim da UFMG, $\mathrm{n}^{\mathrm{O}}$ 1897, Ano 41, 2015. p. 02

FARIA FILHO, L. M. Cultura Escolar e Cultura Urbana no Brasil. Revista Presença Pedagógica, v. 11, n. 66, nov./dez 2005. p. 41

OLIVEIRA, A.M.S. A relação homem/natureza no modo de produção capitalista. Revista Pegada, Presidente Prudente, v. 3, n. Especial, ago. 2002

PRESIDÊNCIA DA REPÚBLICA FEDERATIVA DO BRASIL. Lei Federal no $\mathbf{9 . 3 9 4}$, de 20 de dezembro de 1996. Estabelece as Diretrizes e Bases da Educação Nacional. 
Disponível em: <http://www.planalto.gov.br/ccivil_03/leis/L9394.htm>. Acesso em: 01 ago. 2017.

PRESIDÊNCIA DA REPÚBLICA FEDERATIVA DO BRASIL. Casa Civil. Subchefia para Assuntos Jurídicos. Lei federal $\mathbf{n}^{\mathbf{0}} \mathbf{1 2 . 9 6 0}$, de 27 de março de 2014. Altera a Lei $\mathrm{n}^{\circ}$ 9.394, de 20 de dezembro de 1996, que estabelece as diretrizes e bases da educação nacional, para fazer constar a exigência de manifestação de órgão normativo do sistema de ensino para o fechamento de escolas do campo, indígenas e quilombolas. Disponível em: < http://www.planalto.gov.br/ccivil_03/_ato2011-2014/2014/lei/ 112960.htm >. Acesso em: 01 ago. 2017.

Recebido em: 29/10/2017

Aceito em: 29/03/2018 